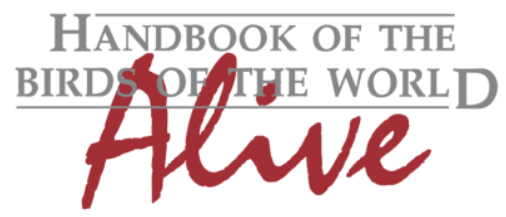

\title{
ORNITHOLOGICAL NOTES
}

\section{Notes on the vocalizations of Metallic-winged Sunbird (Aethopyga pulcherrima)}

\section{Peter Boesman}

In the following we briefly analyze and compare voice of the three races of Metallic-winged Sunbird (Aethopyga pulcherrima). We also try to quantify the extent of any vocal differences using the criteria proposed by Tobias et al. (2010), as a support for taxonomic review.

We have made use of sound recordings available on-line from Xeno Canto (XC) and Macaulay Library (ML).

A comparison of voice based on the available recordings, illustrated with sonograms:

\section{pulcherrima}

Song-like vocalization is a high-pitched continuous twittering with trills, repeated or alternating notes, in fast phrases and slower-paced parts.

Some examples:

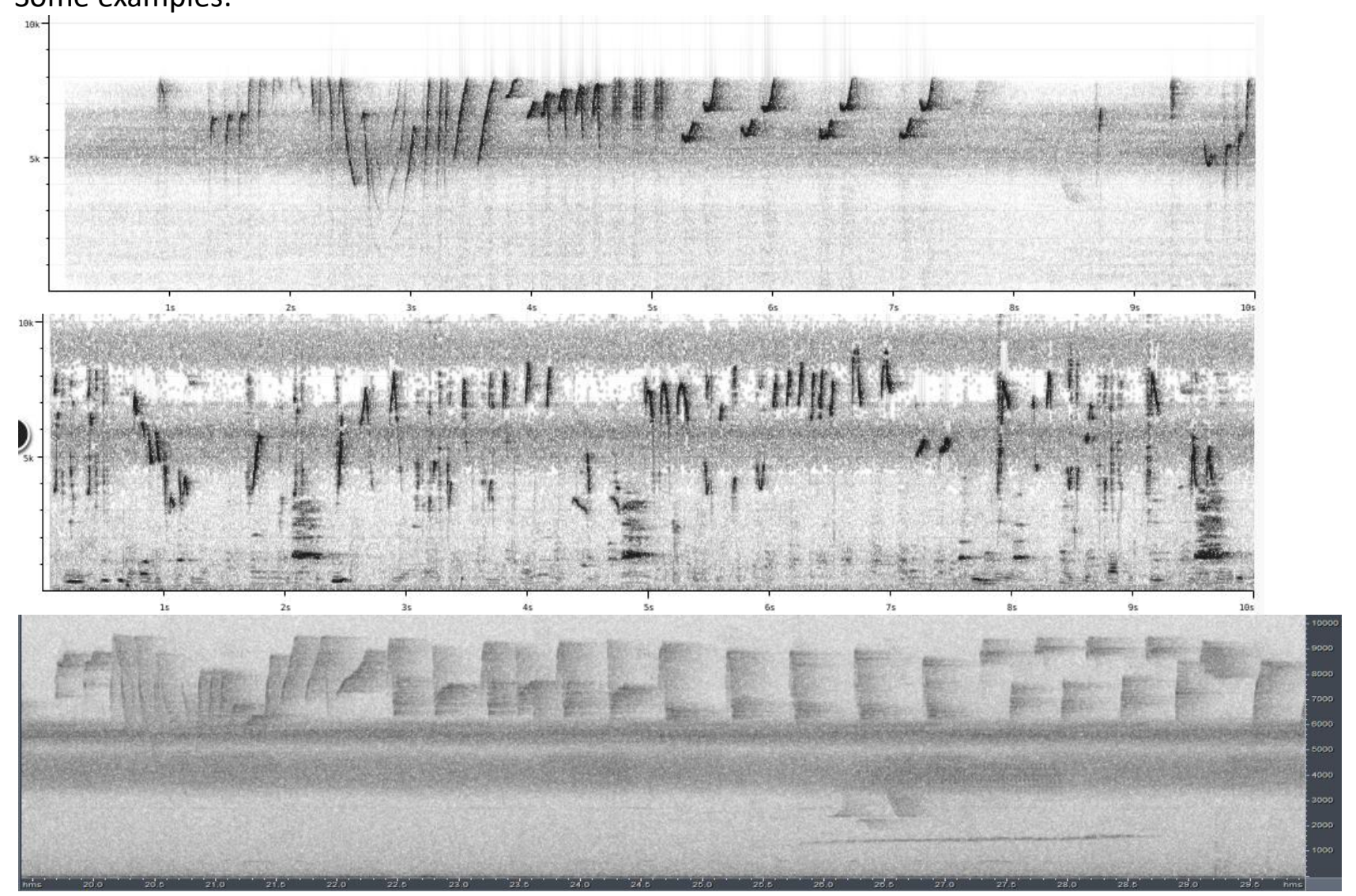




\section{HANDBOOK OF THE \\ Alve}

\section{ORNITHOLOGICAL NOTES}

Another frequently heard vocalization is a high-pitched short "tsik", often repeated, either at regular pace or in irregular series.
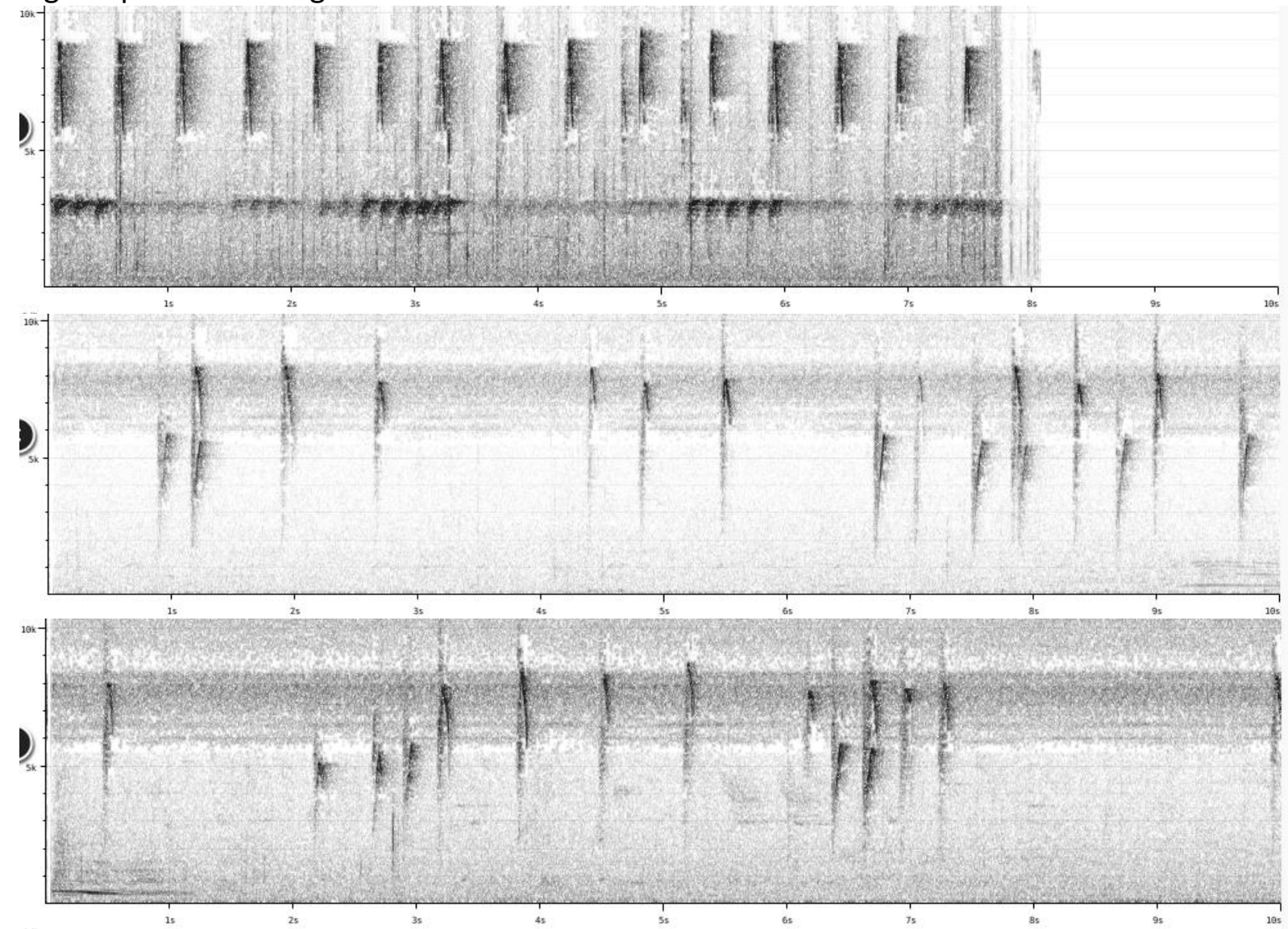

jefferyi

Song-like vocalizations are phrases of high-pitched notes and a long series of identical notes repeated (slightly rising in pitch at first).
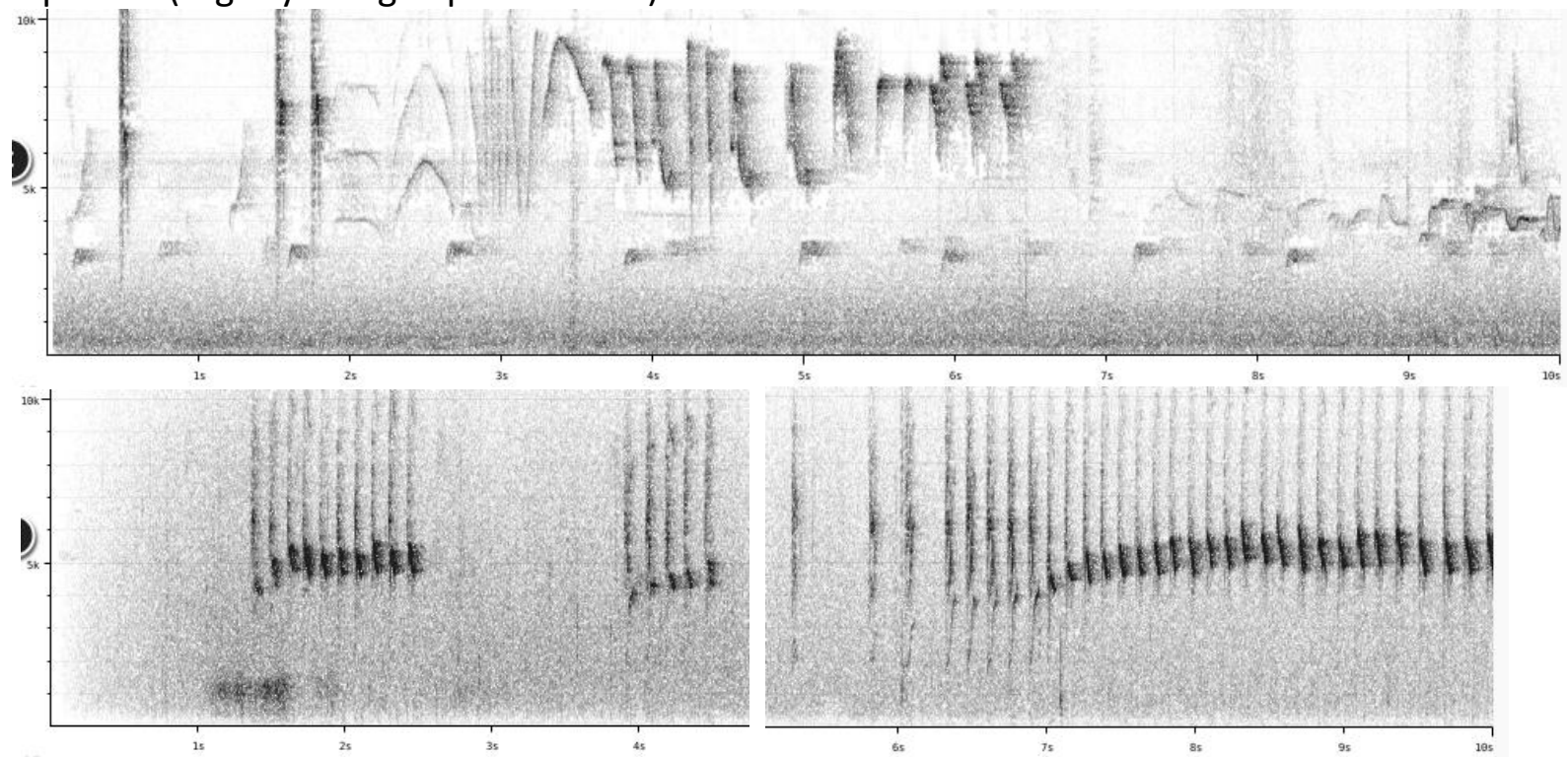


\section{HANDBOOK OF THE \\ BIRDSPF THE WORLD}

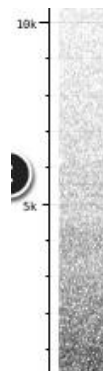

\section{ORNITHOLOGICAL NOTES}

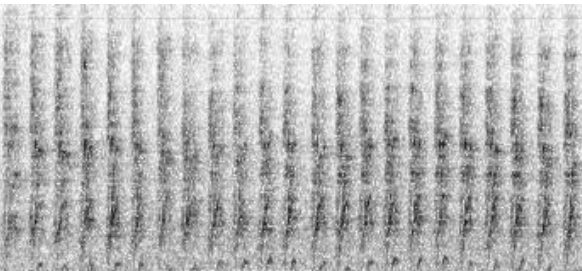

Also a high-pitched short "tsik", often repeated, either at regular pace or in irregular series.

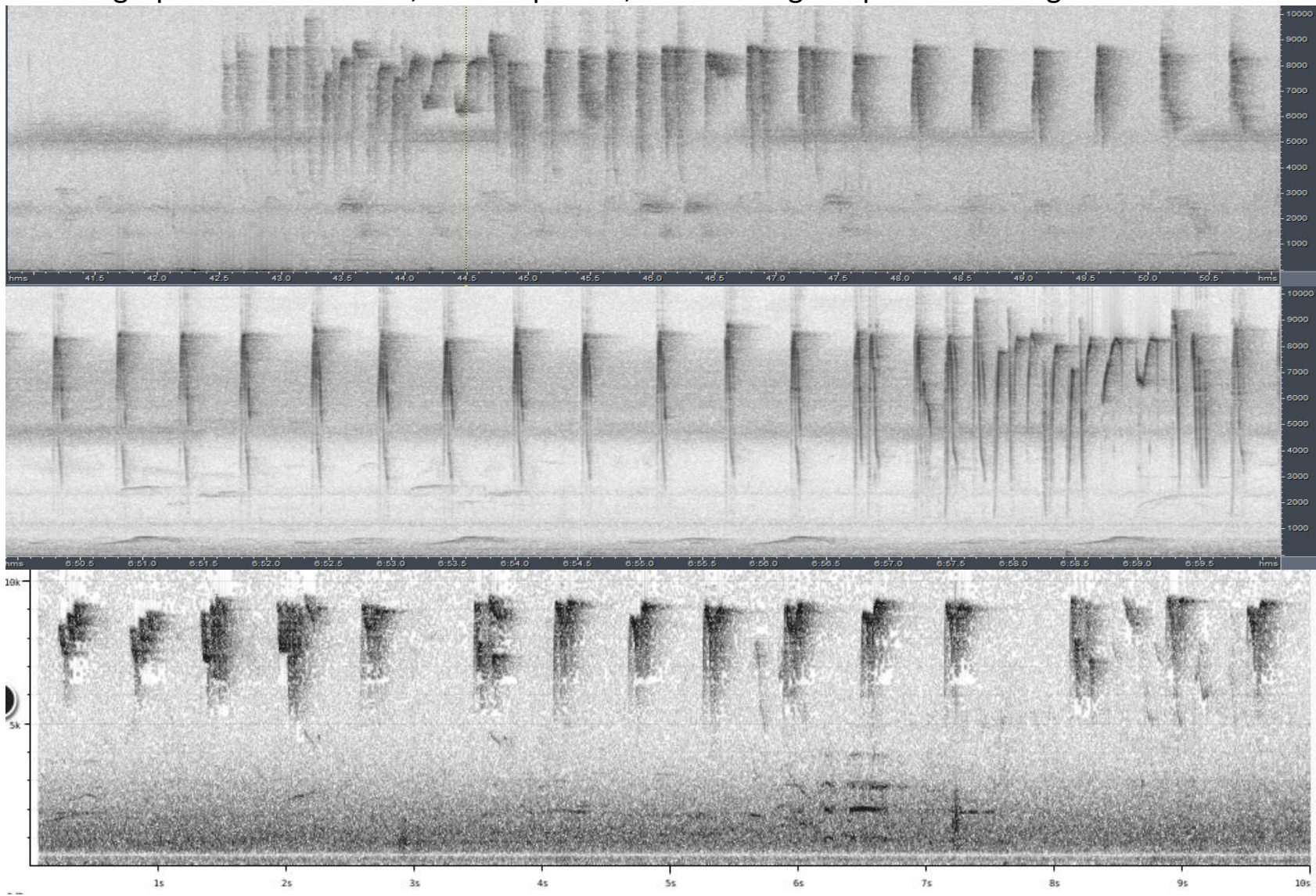

decorosa $(n=1)$

Call

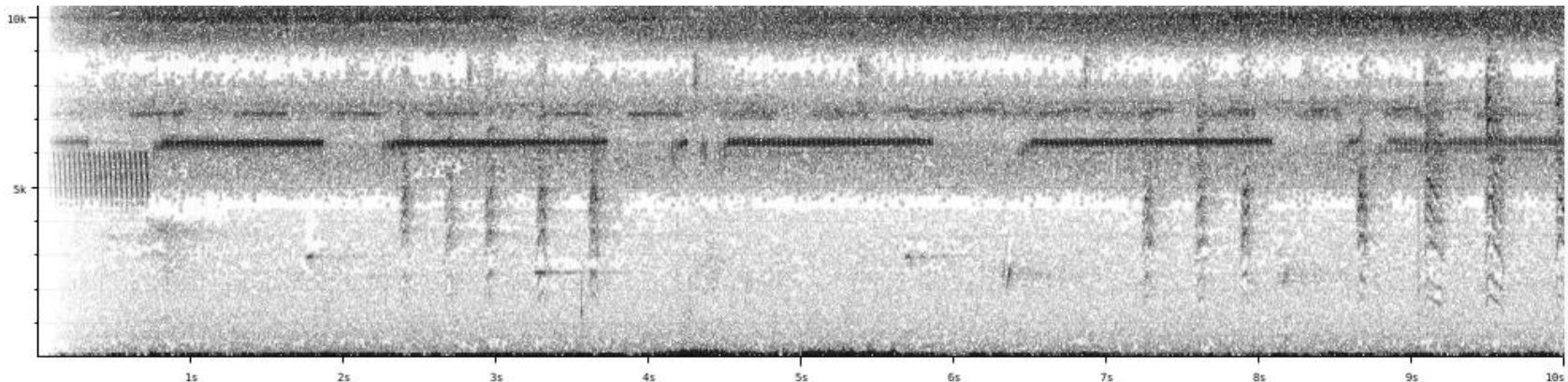

The single recording of a (distress?) call note does not seem to have an equivalent in the two other races. Not much more can be said for this race. 

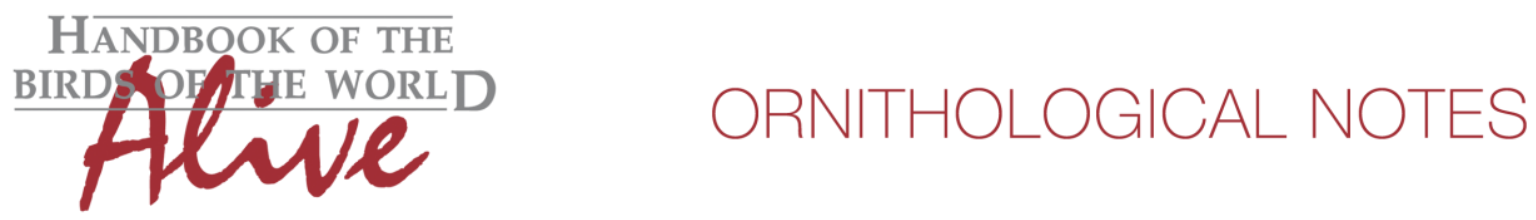

When comparing nominate with jefferyi, we can observe that both races share the long series of a single high-pitched note repeated (same note shape), with periodic more varied twittered sequences.

Both races also seem to have twittered phrases without this periodic single note.

jefferyi also has a lower-pitched long phrase of notes repeated, which apparently hasn't been recorded for nominate.

All in all, there is no strong indication of significant vocal differences, but more recordings would be needed to have a better understanding of the vocal repertoire of both races.

If the trilled phrase is truly unique to jefferyi and frequently uttered, a score of about 2 could be allowed.

This note was finalized on 28th April 2016, using sound recordings available on-line at that moment. We would like to thank in particular the sound recordists who placed their recordings for this species on XC and ML: Desmond Allen, David Edwards, Stijn De Win, Frank Lambert, Mike Nelson and Paul Noakes.

\section{References}

Tobias, J.A., Seddon, N., Spottiswoode, C.N., Pilgrim, J.D., Fishpool, L.D.C. \& Collar, N.J. (2010). Quantitative criteria for species delimitation. Ibis 152(4): 724-746.

\section{Recommended citation}

Boesman, P. (2016). Notes on the vocalizations of Metallic-winged Sunbird (Aethopyga pulcherrima). HBW Alive Ornithological Note 342. In: Handbook of the Birds of the World Alive. Lynx Edicions, Barcelona. (retrieved from http://www.hbw.com/node/1252866 on 26 October 2016). 